\title{
Alice Delphine Tang, Patricia Bissa Enama (dir.), Absence, enquête et quête dans le roman francophone
}

Ilaria Vitali

\section{Q OpenEdition}

\section{Edizione digitale}

URL: http://journals.openedition.org/studifrancesi/3883

DOI: $10.4000 /$ studifrancesi.3883

ISSN: 2421-5856

\section{Editore}

Rosenberg \& Sellier

\section{Edizione cartacea}

Data di pubblicazione: 1 décembre 2012

Paginazione: 616

ISSN: 0039-2944

\section{Notizia bibliografica digitale}

Ilaria Vitali, «Alice Delphine Tang, Patricia Bissa Enama (dir.), Absence, enquête et quête dans le roman francophone», Studi Francesi [Online], 168 (LVI | III) | 2012, online dal 30 novembre 2015, consultato il 06 mars 2021. URL: http://journals.openedition.org/studifrancesi/3883 ; DOI: https://doi.org/10.4000/ studifrancesi.3883

Questo documento è stato generato automaticamente il 6 mars 2021.

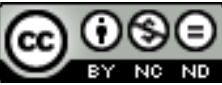

Studi Francesi è distribuita con Licenza Creative Commons Attribuzione - Non commerciale - Non opere derivate 4.0 Internazionale. 


\title{
Alice Delphine Tang, Patricia Bissa Enama (dir.), Absence, enquête et quête dans le roman francophone
}

\author{
Ilaria Vitali
}

\section{NOTIZIA}

ALICE DELPHINE TANG, PATRICIA BISSA ENAMA (dir.), Absence, enquête et quête dans le roman francophone, Bruxelles, P.I.E. Peter Lang, 2010, pp. 314.

1 La scelta di lanciare una riflessione sul tema «absence, enquête et quête» nel romanzo francofono non è, stando alle parole del prefatore Justin Bisanswa, né innocente né neutra. Essa implica infatti un ripensamento e un nuovo sguardo sul processo dell'atto della scrittura nonché dell'atto della lettura. Le tre nozioni fondamentali presenti del titolo non sono «spiegate» né articolate in prospettiva storica, sono però affrontate in maniera originale dagli studiosi, che le declinano in maniera «letterale» ma anche «laterale», come spiega la ricca prefazione del volume. Per quanto riguarda il campo d'indagine, occorre sottolineare che la raccolta di questi studi, che si rivolgono a un pubblico di specialisti del settore, non intende soffermarsi sulla definizione di romanzo - genere inglobante di cui si conoscono da tempo le labili frontiere - né sullo statuto linguistico e letterario della francofonia e delle sue istituzioni - su cui esiste già una ricca bibliografia. Partendo da questi assunti, l'obiettivo è quello di andare oltre e di entrare subito in medias res. Il volume raccoglie un nutrito numero di studi, che spaziano dal celebre Mémoires d'Hadrien di Marguerite Yourcenar al più recente Contours du jour qui vient di Léonora Miano.

Ognuno degli elementi presenti nel titolo di questo volume è rappresentato nel suo ventaglio linguistico e culturale più ampio: l'absence, che genera l'indagine, può essere quella della storia, ma anche dell'identità. L'enquête può dipendere allora da un enigma, da un mistero insoluto come nel romanzo di Marie Darrieussecq, ma può essere anche 
inchiesta poliziesca, come nei romanzi di Fred Vargas, e può altresì divenire enquête sociale, (con)quête di una verità che si rivela poco a poco, a partire da indizi e fragili tracce. È il caso, tra gli altri, di Pelourinho di Tierno Monénembo. La quête può essere quella delle origini, come in Modiano, o quella di un'identità del presente e del futuro tutta da costruire, come in Léonora Miano. Quello che emerge in maniera prepotente dall'insieme di questi studi è l'onnipresenza del tema dell'incertezza, della messa in discussione del sé, della crisi identitaria. Forse hanno ragione le curatrici del volume quando affermano che «la littérature moderne se veut de plus en plus lucide et expression d'un malaise». (p. 37)

Ci sembra infine importante segnalare l'emergere di una tendenza sempre più presente negli studi francofoni, che questo volume conferma, ovvero la volontà di inserire nello stesso «recipiente» sia gli autori cosiddetti francofoni sia quelli franco-francesi, classificandoli sotto l'etichetta generica di «francofonia». Coude à coude, troviamo così Marguerite Yourcenar e Mohamed Dib, Tierno Monénembo e Nathalie Sarraute, Léonora Miano e Didier Daeninckx. Un elemento forse «laterale» rispetto al contenuto del volume, ma su cui vale la pena di riflettere. 